\title{
Ligating the Ductus Arteriosus before Birth Causes Persistent Pulmonary Hypertension in the Newborn Lamb
}

\author{
FREDERICK C. MORIN III \\ Departments of Pediatrics and Physiology, State University of New York at Buffalo, Buffalo, New York 14214
}

\begin{abstract}
We determined whether closing the ductus arteriosus of the fetal lamb several $d$ before birth would cause persistent pulmonary hypertension after birth. Six experimental fetuses who had their ductus arteriosus ligated 3-17 d before delivery, three control fetuses who had sham ligation of the ductus arteriosus $14 \mathrm{~d}$ before delivery, and six control fetuses who had no prenatal surgery were delivered by cesarean section between 138 and $144 \mathrm{~d}$ of gestation. Each was instrumented to measure pulmonary and systemic arterial pressures and pulmonary blood flow. Each newborn lamb was ventilated with room air during the first $45 \mathrm{~min}$ after birth and then with decreasing amounts of inspired oxygen from 100 to $9 \%$. Pulmonary arterial pressure decreased significantly when ventilation was begun in the control lambs but not in the lambs who had their ductus arteriosus ligated before delivery. Throughout the experiment, pulmonary arterial pressure and total pulmonary resistance were significantly higher, and pulmonary blood flow was significantly lower in the lambs who had their ductus arteriosus ligated before delivery. In two of them, pulmonary arterial pressure was greater than or equal to systemic arterial pressure, even during ventilation with $100 \%$ oxygen. This animal preparation provides a method of investigating persistent pulmonary hypertension in the newborn lamb and may provide insight into an etiology of the syndrome of persistent pulmonary hypertension of the newborn. (Pediatr Res 25:245-250, 1989)
\end{abstract}

In the pulmonary circulation of the adult and, even more strikingly, of the newborn, chronic alveolar hypoxia causes vasoconstriction, hypertension, and remodeling of the vasculature (1-5). If alveolar oxygen tension is returned to normal, initially pulmonary arterial pressure remains severely elevated, then it decreases toward normal over days $(3,5)$. The pulmonary circulation of the fetus has many of the characteristics which produce this persistent pulmonary hypertension in the adult or newborn. Its oxygen tension would be considered hypoxic after birth and causes intense vasoconstriction (6). Its arterial pressure is high, being equal to systemic arterial pressure $(7,8)$. The muscular coats of its preacinar, arteries are thickened (9). Despite these similarities to the adult pulmonary circulation during chronic hypoxia, pulmonary arterial pressure drops sharply in the newborn when alveolar oxygen tension increases at birth (7, 8).

Why do all newborns not have persistent pulmonary hyperten-

Received July 25, 1988; accepted October 27, 1988.

Correspondence Frederick C. Morin III, M.D., Division of Neonatology, Children's Hospital of Buffalo, 219 Bryant Street, Buffalo, NY 14222.

Supported by NIH Grant 1 PO1 HL 34323. sion? There are at least two major differences between the pulmonary circulation of the fetus and that of the adult during chronic hypoxia. In the fetus, right ventricular output is shunted away from the lungs across the ductus arteriosus $(7,8)$ and the peripheral, intraacinar arteries of the pulmonary ciruclation are not remodeled (9). Perhaps the diversion of right ventricluar output somehow protects the intraacinar arteries and prevents the development of persistent pulmonary hypertension $(10,11)$. There are reports of long-term survival of the fetus after closure of the ductus arteriosus $(12,13)$. We performed this study to determine whether closing the ductus arteriosus of the fetal lamb several d before birth would cause persistent pulmonary hypertension after birth.

\section{MATERIALS AND METHODS}

A total of 21 fetal lambs were used for this study. Term gestation in sheep is $146 \mathrm{~d}$. Twelve experimental fetuses had their ductus arteriosus ligated when they were between 123 and $135 \mathrm{~d}$ of gestation, 3-17 d before delivery. Three control fetuses had sham ligation of the ductus arteriosus when they were 127 $\mathrm{d}$ of gestation, $14 \mathrm{~d}$ before delivery. Six control lambs had no surgery before delivery. Each surviving fetus was delivered between 138 and $144 \mathrm{~d}$ of gestation.

Ligation and sham ligation of ductus arteriosus before delivery. Each of 15 pregnant ewes was induced into anesthesia with an intravenous injection of sodium thiamylal. Surgery was then performed under halothane anesthesia. The uterus was exposed through a midline abdominal incision, and the left forearm of the fetus was delivered through a uterine incision. A thoracotomy was performed in the left third intercostal space of the fetus, and the pericardium was opened. In the 12 experimental fetuses, the intrapericardial portion of the ductus arteriosus was closed with a ligature of umbilical tape. In the three sham-operated control fetuses, the ductus arteriosus was visualized but not ligated. The fetal chest wall was closed and the forearm returned to the uterus. Ampicillin $300 \mathrm{mg}$ and gentamicin $12 \mathrm{mg}$ were injected into the amniotic sac. The uterus and maternal abdominal wall were closed. The fetus and ewe were allowed to recover from anesthesia. The ewe received $700 \mathrm{mg}$ of ampicillin and $28 \mathrm{mg}$ of gentamicin intramuscularly each day for $3 \mathrm{~d}$.

In addition to the above surgery, the first three experimental lambs had catheters placed in the right atrium, pulmonary artery, and aorta to allow sequential measurement of vascular pressures and of pulmonary blood flow by the radioactive microsphere technique (6). Because only one of these fetuses survived to delivery, prenatal catheterization and radioactive microsphere injections were then eliminated from the protocol.

Surgery at delivery. For each surviving fetus, anesthesia was induced and maintained as just described. The fetus was delivered, with the umbilical circulation intact, through a flank incision in the ewe. It was placed in a plastic bag to prevent 
evaporative heat loss and was kept warm with a heating pad and a radiant lamp. A tracheostomy was performed. A clamped tube with ports for measurement of pressure and expired gases was inserted such that the ports were immediately above the tracheostomy. A cutdown was performed on the carotid artery, and a catheter was passed into the ascending aorta. A cutdown was performed on the jugular vein, and a catheter was passed into the right atrium. A temperature transducer was inserted into the rectum.

A thoracotomy was then performed in the left third intercostal space. An electromagnetic flow transducer was placed around the main pulmonary artery and a catheter inserted into the artery. In some fetuses, a catheter was inserted directly into the left atrium. The control fetuses had the ductus arteriosus ligated at this point so that the transducer around the main pulmonary artery measured pulmonary blood flow in both experimental and control lambs. The tracheostomy tube was unclamped and ventilation begun. The umbilical cord was immediately ligated and cut, and the newborn lamb received ketamine $5 \mathrm{mg} / \mathrm{kg}$ intravenously with additional doses when necessary to maintain anesthesia.

Experimental protocol. The newborn lambs were ventilated at a tidal vol of approximately $10 \mathrm{ml} / \mathrm{kg}$ with $20 \mathrm{ml} / \mathrm{kg}$ sighs at $15-$ min intervals. End expiratory pressure was maintained at $2 \mathrm{~cm}$ of water. Ventilator rate was adjusted to maintain end tidal carbon dioxide concentration at $5 \%$. During the first $45 \mathrm{~min}$, the lambs were ventilated with room air. Then their response to changes in alveolar oxygen tension was determined by ventilating them with $100,50,21,15$, and $9 \%$ oxygen for 5 -min periods. In preliminary experiments, three identically instrumented newborn lambs were exposed to these fractions of inspired oxygen in this order and in reverse order. Average pulmonary arterial pressure, blood flow, and resistance, and blood gases at a given fraction of inspired oxygen varied by $\leq 10 \%$ between the orders of exposure.

At the end of the experiment, each lamb was sacrificed with phenobarbital. The position of the right atrial catheter was checked. The ductus arteriosus was examined to insure it was closed to inspection and did not allow passage of a $1.5-\mathrm{mm}$ probe.

Measurements. The following phasic variables were recorded continuously: pulmonary and systemic arterial pressure, right and left atrial pressure, airway pressure, pulmonary blood flow, and expired oxygen and carbon dioxide concentrations. Every $15 \mathrm{~min}$ for the first $45 \mathrm{~min}$ and at the end of each exposure to a new oxygen concentration, electronically meaned values of each of the phasic variables, except expired gases, were recorded, and a systemic arterial blood sample for measurement of $\mathrm{pH}$ and the tensions of oxygen and carbon dioxide was obtained.

Expired gases were analyzed by a Perkin-Elmer MGA 1100 mass spectrometer (Perkin-Elmer Corp., Norwalk CT). Vascular pressures were measured by Bentley Trantec transducers. Airway pressure was measured by a Gould-Statham differential pressure transducer. Pulmonary blood flow was measured by a C\&C Instruments electromagnetic flow transducer and analyzed by a Gould SP2202 electromagnetic flowmeter (Gould Inc., Oxnard, $\mathrm{CA}$ ). Each of these variables was processed and recorded by a Gould physiologic amplifier recorder system. Blood gas tensions, $\mathrm{pH}$, and $\mathrm{Hb}$ were measured by a Radiometer ABL2. Rectal temperature was measured by a Yellow Springs Instruments Co. (Yellow Springs, $\mathrm{OH}$ ) telethermometer and maintained at 39$40^{\circ} \mathrm{C}$.

The one experimental fetus that had been catheterized prenatally and survived to delivery spontaneously $6 \mathrm{~d}$ after ligation of the ductus arteriosus was studied by a different protocol. It was placed in a chamber which allowed it to walk about and feed while the $\mathrm{Fi}_{\mathrm{O}_{2}}$ in the chamber was varied between 0.21 and 1.0. Pulmonary and systemic arterial pressures and systemic arterial blood gases and $\mathrm{pH}$ were monitored under these conditions for $2 \mathrm{~d}$.
Data analysis. All pressures were referenced to the midchest. Pulmonary blood flow was corrected for body wt in $\mathrm{kg}$. Total pulmonary resistance was calculated as pulmonary arterial pressure/pulmonary blood flow $/ \mathrm{kg}$. Left atrial pressure was not used as it was not consistently available (Table 1). The ratio of pulmonary arterial to systemic arterial pressure was determined.

Factorial ANOVA with repeated measures applied to the first factor (time or $\mathrm{Fi}_{\mathrm{O}_{2}}$ ) was used to determine if the pulmonary circulatory variables changed with time or with $\mathrm{Fi}_{\mathrm{O}_{2}}$ and whether they are different between the control lambs and those with prenatal ligation of the ductus arteriosus (14). To maintain equal group sizes, these analyses compared the six surviving lambs that had prenatal ligation of the ductus arteriosus without catheterization to the six control lambs that had no prenatal surgery. Regression of pulmonary arterial pressure, blood flow, and resistance on d of ligation of the ductus arteriosus before birth was analyzed using the data at the end of the first $45 \mathrm{~min}$ of ventilation with air. To avoid skewing the data with a large number of points at $0 \mathrm{~d}$ of ligation, this analysis was applied to the data from the three sham-operated control lambs and the six surviving lambs with prenatal ligation of the ductus arteriosus without catheterization. The one surviving lamb that had prenatal catheterization is summarized separately.

\section{RESULTS}

Three of the nine fetuses who had prenatal ligation of the ductus arteriosus without catheterization died before study. Two were found dead after spontaneous delivery while unattended. These two were heavily stained with meconium and had inflated lungs, indicating live birth. One died during insertion of a left atrial catheter after cesarean section.

Hemodynamics. During the first 45 min of ventilation with air, pulmonary arterial pressure decreased in the control lambs without prenatal surgery but not in the lambs who had their ductus arteriosus ligated 3-17 d before delivery (Fig. 1A). During this period, pulmonary arterial pressure was higher, pulmonary blood flow was lower, and total pulmonary resistance was higher in the lungs of the lambs who had their ductus arteriosus ligated before delivery.

During the variation in inspired oxygen from 100 to $9 \%$, pulmonary arterial pressure remained higher, pulmonary blood flow lower, and total pulmonary resistance higher in the lambs who had their ductus arteriosus ligated before delivery (Fig. $1 B$ ). Decreasing $\mathrm{Fi}_{\mathrm{O}_{2}}$ increased pulmonary arterial pressure and resistance in both groups of lambs.

Prenatal thoracotomy alone did not cause pulmonary hypertension. The ratio of pulmonary arterial pressure in the shamoperated control lambs to that in the control lambs without prenatal surgery averaged $0.98 \pm 0.03$ over the course of the experiment. Similarly, the ratio of pulmonary blood flow in the sham-operated to the unoperated control lambs averaged $1.33 \pm$ 0.03 .

Aortic pressure tended to be lower in the lambs with prenatal ligation of the ductus arteriosus, though the tendency did not reach significance (Table 1). Right atrial pressure was higher in the lambs who had prenatal ligation of the ductus arteriosus. This was a very similar elevation of left atrial pressure in the three lambs with prenatal ligation in whom measurements were made. The higher total pulmonary resistance was not due to this elevation of left atrial pressure. If pulmonary vascular resistance is calculated in all lambs using right atrial pressure as an index of left atrial pressure, it remains significantly elevated in the lambs with prenatal ligation of the ductus arteriosus.

Pulmonary arterial pressure approximated systemic arterial pressure throughout the experiment in the lambs that had their ductus arteriosus ligated before delivery. During the variation in inspired oxygen, the ratio of pulmonary to systemic arterial pressure averaged 1.02 on room air (Fig. 2) and in two lambs it was at least 1.0 , even during ventilation with $100 \%$ oxygen. The 
Table 1. Heart rate and systemic arterial and atrial pressures during the first 45 min of ventilation with air and during variation in $\mathrm{Fi}_{\mathrm{O}_{2}}$ in six control newborn lambs and six lambs that had their ductus arteriosus ligated before delivery*

\begin{tabular}{|c|c|c|c|c|c|c|c|c|}
\hline \multirow[b]{3}{*}{$\mathrm{Fi}_{\mathrm{O}_{2}}$} & \multicolumn{2}{|c|}{ Heart rate (beats/min) } & \multicolumn{6}{|c|}{ Mean pressure (torr) } \\
\hline & \multirow[b]{2}{*}{ Control } & \multirow[b]{2}{*}{ Ligated } & \multicolumn{2}{|c|}{ Systemic arterial } & \multicolumn{2}{|c|}{ Right atrial } & \multicolumn{2}{|c|}{ Left atrial } \\
\hline & & & Control & Ligated & Control & Ligated & $\begin{array}{l}\text { Control } \\
(n=3)\end{array}$ & $\begin{array}{l}\text { Ligated } \\
(n=3)\end{array}$ \\
\hline \multicolumn{9}{|l|}{0.21} \\
\hline$(15 \mathrm{~min})$ & $147 \pm 8$ & $173 \pm 13$ & $84 \pm 4$ & $62 \pm 5$ & $-1 \pm 2$ & $5 \pm 1$ & $0 \pm 1$ & $5 \pm 1$ \\
\hline$(30 \min )$ & $164 \pm 9$ & $177 \pm 12$ & $83 \pm 5$ & $65 \pm 5$ & $-2 \pm 1$ & $4 \pm 1$ & $0 \pm 2$ & $4 \pm 1$ \\
\hline$(45 \mathrm{~min})$ & $\begin{array}{c}159 \pm 7 \\
\dagger\end{array}$ & $\begin{array}{c}175 \pm 18 \\
\dagger\end{array}$ & $78 \pm 4$ & $62 \pm 5$ & $\begin{array}{c}-3 \pm 1 \\
+\end{array}$ & $\begin{array}{c}4 \pm 1 \\
+ \pm\end{array}$ & $-1 \pm 2$ & $4 \pm 1$ \\
\hline 1.0 & $155 \pm 5$ & $155 \pm 16$ & $73 \pm 5$ & $61 \pm 6$ & $-3 \pm 1$ & $4 \pm 1$ & $-1 \pm 1$ & $3 \pm 1$ \\
\hline 0.5 & $160 \pm 4$ & $160 \pm 16$ & $72 \pm 5$ & $59 \pm 6$ & $-3 \pm 1$ & $4 \pm 1$ & $0 \pm 1$ & $3 \pm 1$ \\
\hline 0.21 & $161 \pm 5$ & $171 \pm 14$ & $67 \pm 3$ & $54 \pm 6$ & $-3 \pm 1$ & $3 \pm 1$ & $-1 \pm 1$ & $2 \pm 1$ \\
\hline 0.15 & $166 \pm 7$ & $178 \pm 14$ & $66 \pm 4$ & $53 \pm 5$ & $-2 \pm 1$ & $3 \pm 1$ & $-2 \pm 1$ & $2 \pm 1$ \\
\hline 0.09 & $\begin{array}{c}165 \pm 7 \\
\dagger\end{array}$ & $\begin{array}{c}199 \pm 17 \\
\dagger\end{array}$ & $\begin{array}{c}65 \pm 6 \\
\dagger\end{array}$ & $\begin{array}{c}54 \pm 7 \\
\dagger\end{array}$ & $-2 \pm 1$ & $\begin{array}{c}5 \pm 1 \\
\pm\end{array}$ & $-2 \pm 1$ & $2 \pm 1$ \\
\hline
\end{tabular}

* Values are mean \pm SEM.

$\dagger$ Values in the column above change significantly with time or with $\mathrm{Fi}_{\mathrm{O}_{2}}, p \leq 0.05$.

\$Values in the column above are significantly different than those in the control lambs, $p \leq 0.05$.
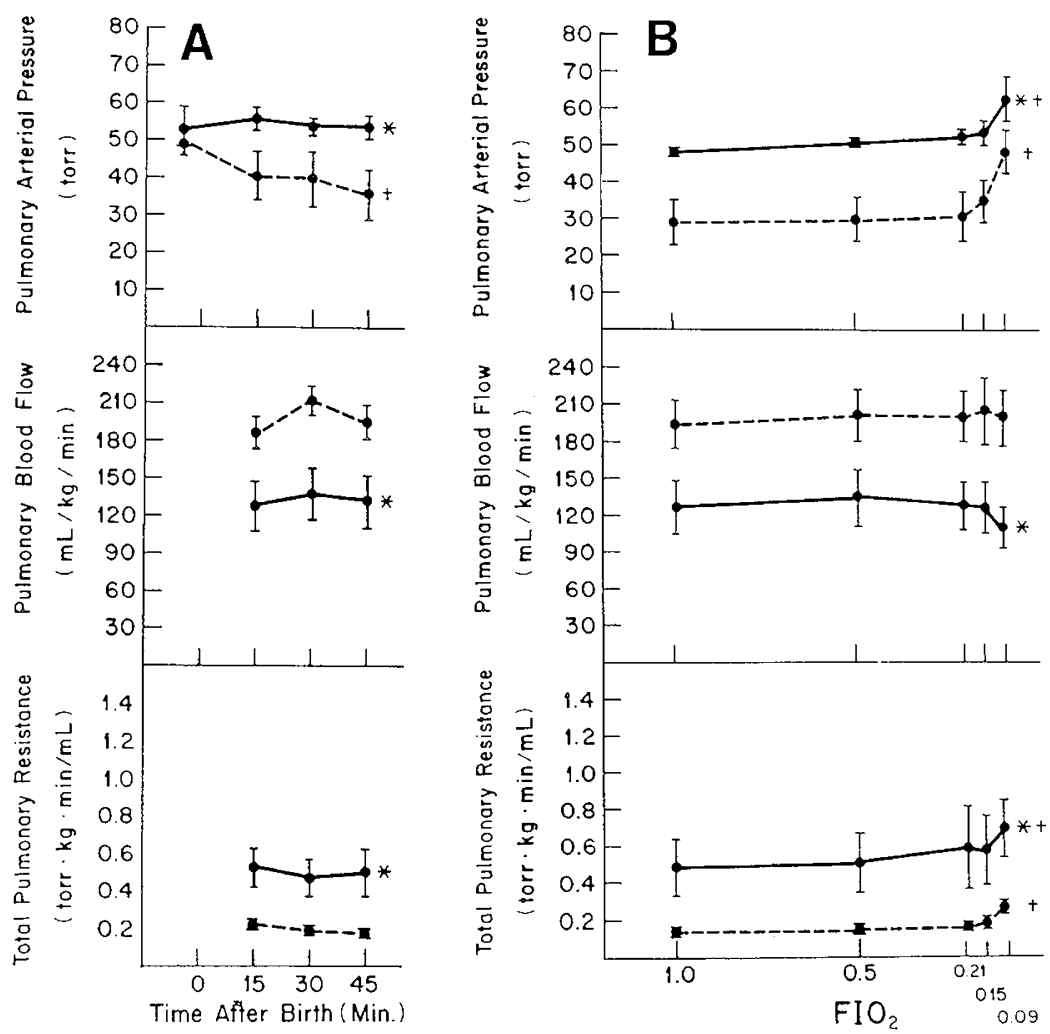

Fig. 1. Pressure, blood flow, and resistance in the pulmonary circulation of six control newborn lambs (broken lines) and six newborn lambs that had their ductus arteriosus ligated 3-17 d before delivery (solid lines). $A$, during the first 45 min of ventilation with room air; $B$, during ventilation with stepwise decreases in $\mathrm{Fi}_{\mathrm{O}_{2}}$ from 1.0 to 0.09 . Values are mean $\pm \mathrm{SEM}$. ${ }^{*}=$ Significantly different than in the control lambs during the first $45 \mathrm{~min}$ of ventilation with air or during the variation in $\mathrm{Fi}_{\mathrm{O}_{2}}, p \leq 0.05 .+=$ Changes significantly with time of with $\mathrm{Fi}_{2} p \leq 0.05$.

longer the ductus arteriosus was ligated, the higher the pulmonary arterial pressure and resistance and the lower the pulmonary blood flow (Fig. 3).

Gas exchange. End tidal tensions of oxygen and carbon dioxide were the same in the lambs that had prenatal ligation of the ductus arteriosus and the controls that had no prenatal surgery. Obtaining the same end tidal gases required a higher ventilator rate and inspiratory pressure in the lambs that had prenatal ligation of the ductus arteriosus, $41.4 \pm 4$ versus $21 \pm 1$ breaths/ $\min (p \leq 0.05)$ and $33 \pm 2$ versus $21 \pm 2$ torr $(p \leq 0.005)$ after $45 \mathrm{~min}$ of ventilation.
Systemic arterial $\mathrm{pH}$ was the same in both groups of lambs (Table 2). Systemic arterial oxygen tension was substantially lower during ventilation with room air in the lambs that had their ductus arteriosus ligated before delivery. During ventilation with $100 \%$ oxygen, the three of these lambs that had the highest pulmonary arterial pressure had evidence of extrapulmonary shunting of blood. Arterial oxygen tensions were $\leq 45$ torr in these lambs, and oxygen tensions were $>100$ torr in each control lamb.

Prenatal thoracotomy did not impair gas exchange after birth. The sham-operated control lambs had ventilator settings and 


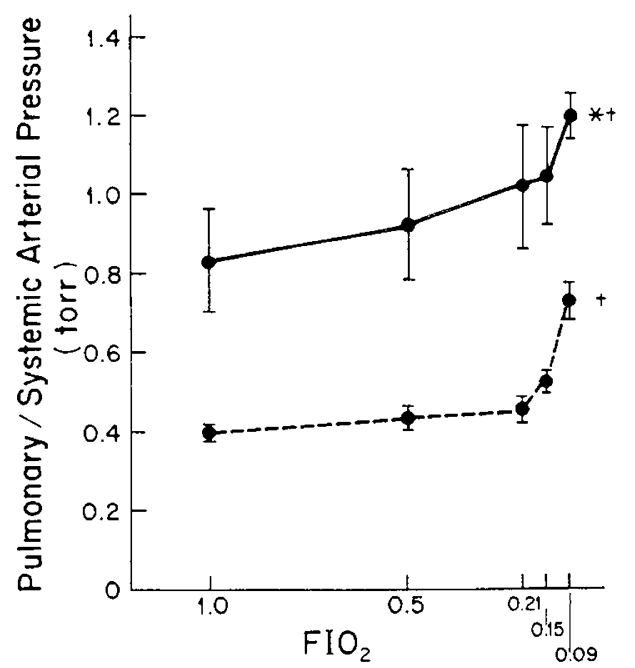

Fig. 2. The ratio of pulmonary to systemic arterial pressure in six control newborn lambs and six newborn lambs that had their ductus arteriosus ligated 3-17 d before delivery. Values are mean \pm SEM. Symbols are as in Figure 1.

arterial oxygen tension similar to the control lambs without prenatal surgery. After $45 \mathrm{~min}$ of room air ventilation, their ventilator rate averaged $19 \pm 3$ breaths/min their inspiratory pressure averaged $14 \pm 2$ torr, and their arterial oxygen tension averaged $66 \pm 4$ torr.

Hemodynamics and gas exchange over $2 d$. In the lamb that had prenatal catheterization, pulmonary arterial pressure was initially quite labile, increasing abruptly with activity (Fig. 4). It was more than systemic arterial pressure except during some of the periods when the lamb breathed $100 \%$ oxygen. Over time, pulmonary arterial pressure stabilized and finally decreased to less than systemic arterial pressure during air breathing. Systemic arterial oxygen tension was initially quite low, but it improved by the end of the experiment.

\section{DISCUSSION}

The newborn lambs that had their ductus arteriosus ligated 3$17 \mathrm{~d}$ before delivery had the physiologic characteristics of newborns with persistent pulmonary hypertension $(15,16)$. Their pulmonary arterial pressure was elevated, often exceeding systemic arterial pressure $(17,18)$. It remained elevated on $100 \%$ oxygen, still exceeding systemic arterial pressure in some (17, 18). Oxygen tension was low $(17,18)$; and there was evidence of extrapulmonary shunting of blood (19) and decreased compliance of the lungs $(16,20-22)$. There was a tendency toward systemic hypotension which may also be an important component of the clinical problem $(5,23)$. In the awake lamb that was studied over time, pulmonary arterial pressure was quite labile, but it eventually stabilized and decreased to less than systemic pressure (16). The accompanying report demonstrates that ligating the ductus arteriosus of fetal lambs causes changes in the anatomy of the pulmonary vascular bed which have been reported in newborns that die from persistent pulmonary hypertension. This experimental animal preparation has the features of persistent pulmonary hypertension of the newborn.

There have been previous attempts to create a newborn animal with the physiologic characteristics of persistent pulmonary hypertension based on the assumption that the syndrome is caused by chronic fetal hypoxia with or without hypercarbia. Thus, investigators have placed pregnant animals in environments with low $\mathrm{Fi}_{\mathrm{O}_{2}}$, embolized the placenta, or partially occluded the umbilical cord (24-26). These approaches should divert even more of the right ventricular output away from the lungs in the fetus (7). In the report on partial occlusion of the umbilical cord, the

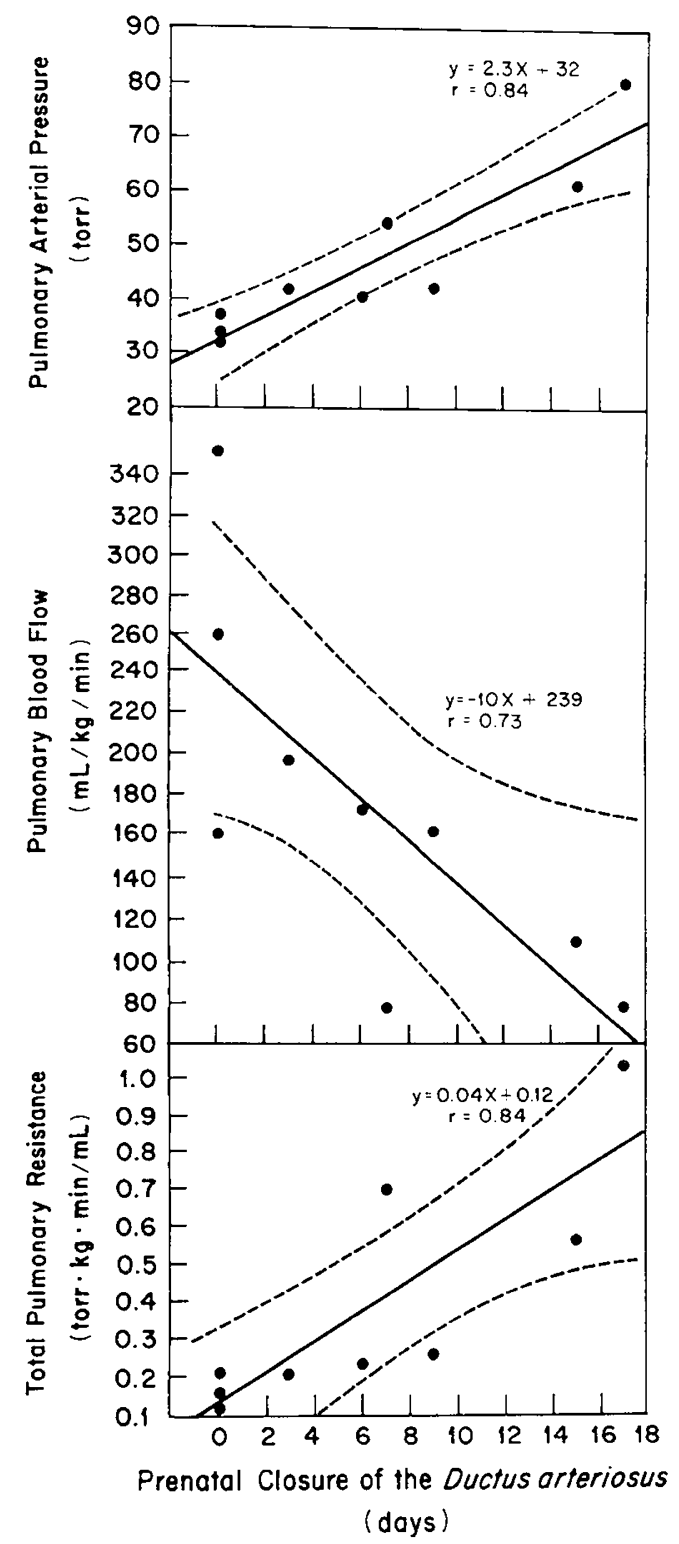

Fig. 3. The regression of pressure, flow, and resistance in the pulmonary circulation of 12 newborn lambs on d of ligation of the ductus arteriosus before delivery. Linear regression lines, their equations, and their $95 \%$ confidence belts are given. Each regression was significant, $p$ $\leq 0.02$.

newborn lambs had elevated pulmonary arterial pressure and resistance relative to control lambs (26). However, during ventilation with air, pulmonary arterial pressure was less than $60 \%$ of systemic arterial pressure, blood shunted left to right across the ductus arteriosus, and oxygenation was normal. In the report of embolizing the placenta, the three treated lambs had elevated pulmonary arterial pressure relative to the control lamb (25). However, pulmonary arterial pressure averaged less than systemic on room air, pulmonary blood flow was not measured, and hypoxemia was not reported. Chronic intrauterine hypoxia alone did not cause pulmonary hypertension in newborn guinea pigs (24).

Based on case reports of persistent pulmonary hypertension in infants of mothers treated with salicylates or indomethacin, prostaglandin synthesis inhibition has been postulated as a cause of the syndrome. Inhibiting prostaglandin synthesis in pregnant ewes constricts the ductus arteriosus, increasing pulmonary arterial pressure above systemic arterial pressure in fetal lambs (27-30). This was associated with a doubling of pulmonary blood 
Table 2. Systemic arterial blood gases and $\mathrm{pH}$ in six control newborn lambs and six lambs that had their ductus arteriosus ligated before delivery*

\begin{tabular}{|c|c|c|c|c|c|c|}
\hline \multirow[b]{2}{*}{$\mathrm{Fi}_{\mathrm{O} 2}$} & \multicolumn{2}{|c|}{$\mathrm{pH}(\mathrm{U})$} & \multicolumn{2}{|c|}{$\mathrm{P}_{\mathrm{CO}_{2}}$ (torr) } & \multicolumn{2}{|c|}{$\mathrm{P}_{\mathrm{O}_{2}}$ (torr) } \\
\hline & Control & Ligated & Control & Ligated & Control & Ligated \\
\hline \multicolumn{7}{|l|}{0.21} \\
\hline$(15 \mathrm{~min})$ & $7.26 \pm 0.02$ & $7.23 \pm 0.05$ & $37 \pm 2$ & $47 \pm 6$ & $50 \pm 6$ & $31 \pm 6$ \\
\hline$(30 \mathrm{~min})$ & $7.29 \pm 0.01$ & $7.28 \pm 0.02$ & $35 \pm 2$ & $43 \pm 1$ & $52 \pm 3$ & $31 \pm 4$ \\
\hline$(45 \mathrm{~min})$ & $\begin{array}{c}7.30 \pm 0.01 \\
\dagger\end{array}$ & $\begin{array}{c}7.29 \pm 0.03 \\
\dagger\end{array}$ & $35 \pm 1$ & $\begin{array}{c}42 \pm 4 \\
\ddagger\end{array}$ & $52 \pm 3$ & $\begin{array}{c}32 \pm 5 \\
\ddagger\end{array}$ \\
\hline 1.0 & $7.33 \pm 0.03$ & $7.33 \pm 0.02$ & $36 \pm 1$ & $39 \pm 2$ & $245 \pm 35$ & $163 \pm 66$ \\
\hline 0.21 & $7.31 \pm 0.02$ & $7.32 \pm 0.02$ & $34 \pm 2$ & $40 \pm 2$ & $56 \pm 2$ & $33 \pm 5$ \\
\hline 0.09 & $7.32 \pm 0.03$ & $7.30 \pm 0.05$ & $34 \pm 2$ & $42 \pm 4$ & $\begin{array}{c}21 \pm 2 \\
\dagger\end{array}$ & $\begin{array}{c}17 \pm 1 \\
\dagger\end{array}$ \\
\hline
\end{tabular}

* Values are mean \pm SEM.

$\uparrow$ Values in the column above change significantly with time or with $\mathrm{Fi}_{\mathrm{O}_{2}}, p \leq 0.05$.

$\$$ Values in the column above are significantly different than those in the control lambs, $p \leq 0.05$.

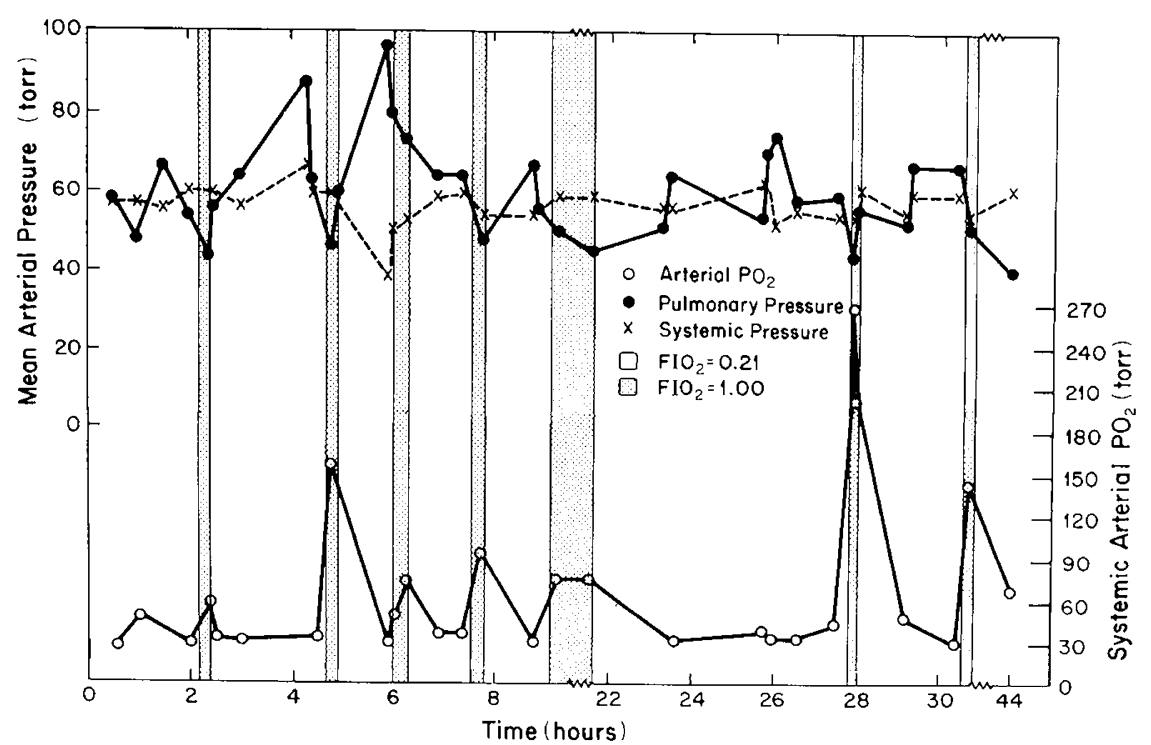

Fig. 4. Pulmonary and systemic arterial pressure and systemic arterial $\mathrm{P}_{\mathrm{O}_{2}}$ during the first $2 \mathrm{~d}$ after birth in an awake lamb that had ligation of the ductus arteriosus $6 \mathrm{~d}$ before spontaneous vaginal delivery.

flow in the report of Heymann and Rudolph (27) and a 5-fold increase in flow in the report of Morin et al. (29). No physiologic studies have been made after birth in the lambs of ewes treated with indomethacin as the fetuses die within a d or two after treatment $(11,28)$. There was a recent study of the effect of indomethacin on the fetal guinea pig (31). This study found that treating the pregnant guinea pig with $7 \mathrm{mg} / \mathrm{kg} /$ day of indomethacin did not cause persistent pulmonary hypertension at birth. Treating the pregnant guinea pig larger doses of indomethacin caused fetal death.

There are previous reports of long-term survival of the fetus after mechanical closure of the ductus arteriosus $(12,13)$. We have found that most fetal lambs survive for many days after mechanical closure of the ductus arteriosus. It is possible that the fetal deaths after maternal indomethacin administration are due to effects of prostaglandin synthesis inhibition other than closure of the ductus arteriosus such as the increase in uterine vascular resistance $(32,33)$.

Mechanical closure of the ductus arteriosus increases pulmonary arterial pressure above systemic arterial pressure in the fetus $(12,13,34,35)$. It also increases pulmonary blood flow out of proportion to the increase in pressure, thus decreasing calculated pulmonary vascular resistance $(8,35)$. It is not clear how long the increase in pressure and flow are maintained. Sequential measurements of pulmonary vascular pressures and blood flow after closure of the ductus arteriosus need to be made. Then the relationship of these factors to the remodeling of the intraacinar arteries and the development of persistent pulmonary hypertension at birth can be determined.

This experimental animal preparation can be used to study the effects of pulmonary hypertension on the transition from gas exchange by the placenta to gas exchange by the lungs at birth. Such study should enhance our understanding of, and management of, newborns with persistent pulmonary hypertension (15). Does this preparation also provide insight into an etiology of persistent pulmonary hypertension of the newborn? Case reports indicate the ductus arteriosus can close before birth (36). Persistent pulmonary hypertension is commonly reported in postterm newborns $(16,17)$. The ductus arteriosus may become more sensitive to constricting stimuli toward term $(37,38)$. It is plausible that the ductus arteriosus is prone to intrauterine constriction, or closure, when the fetus passes term gestation.

Acknowledgments. The author thanks Dr. Edmund A. Egan for advice on the manuscript, Daniel D. Swartz for expert technical assistance, and Lisa LaMonte for assistance with the manuscript.

\section{REFERENCES}

1. Custer JR, Hales CA 1985 Influence of alveolar oxygen on pulmonary vasoconstriction in newborn lambs versus sheep. Am Rev Respir Dis 132:326331 
2. Hislop A, Reid L 1976 New findings in pulmonary arteries of rats with hypoxiainduced pulmonary hypertension. Br J Exp Pathol 57:542-554

3. Rabinovitch M, Gamble WJ, Miettinen OS, Reid L 1981 Age and sex influence on pulmonary hypertension of chronic hypoxia and on recovery. Am J Physiol 240:H62-H72

4. Arias-Stella J, Saladana M 1963 The terminal portion of the pulmonary arterial tree in people native to high altitude. Circulation 28:915

5. Stenmark KR, Fasules J, Hyde DM, Voelkel NJ, Henson J, Tucker A, Wilson H, Reeves JT 1987 Severe pulmonary hypertension and arterial adventitial changes in newborn calves at 4,300m. J Appl Physiol 62:821-830

6. Morin FC, Egan EA, Ferguson W, Lundgren CEG 1988 The development of the pulmonary vascular response to oxygen. Am J Physiol 254:H542-H546

7. Rudolph AM 1984 Congenital Diseases of the Heart. Yearbook Medical Publishers, Inc.

8. Dawes G 1968 Fetal and Neonatal Physiology. Yearbook Medical Publishers, Chicago, IL

9. Geggel RL, Reid LM 1984 The structural basis of PPHN. Clin Perinatol 11:517-525

10. Rabinovitch M, Konstam MA, Gamble WJ, Papanicolaou N, Aronovitz MJ, Treves S, Reid L 1983 Changes in pulmonary blood flow affect vascular response to chronic hypoxia in rats. Circ Res 52:432-441

11. Levin DL, Mills LJ, Weinberg AG 1979 Hemodynamic, pulmonary vascular, and myocardial abnormalities secondary to pharmacologic constriction of the fetal ductus arteriosus. Circulation 60:360-364

12. Haller JA, Rodgers BM 1968 Hemodynamic effects of occluding the fetal ductus arteriosus. Am Surg 34:200-204

13. Ruiz V, Piasecki GJ, Balogh K, Polansky BJ, Jackson BT 1972 An experimental model for fetal pulmonary hypertension: a preliminary report. Am J Surg 123:468-471

14. Wallenstein S, Zucker CL, Fleiss JL 1980 Some statistical methods useful in circulation research. Circ Res 47:1-9

15. Phillips JB (ed) 1984 Neonatal pulmonary hypertension. In: Clinics in Perinatology. WB Saunders Company, Philadelphia

16. Fox WW, Duara S 1983 Persistent pulmonary hypertension in the neonate: diagnosis and management. J Pediatr 103:505-514

17. Drummond WH, Peckham GJ, Fox WW 1977 The clinical profile of the newborn with pulmonary hypertension. Clin Pediatr (Phila) 16:335-341

18. Fox WW, Gewitz MH, Dinwiddie R, Drummond WH, Peckham GJ 1977 Pulmonary hypertension in the perinatal aspiration syndromes. Pediatrics 59:205-211

19. Valdes-Cruz LM, Dudell GG, Ferrara A 1981 Utility of M-mode echocardiography for early identification of infants with persistent pulmonary hyperten sion of the newborn. Pediatrics 68:515-525

20. Yeh TF, Lilien LD 1981 Altered lung mechanics in neonates with persistent fetal circulation syndrome. Crit Care Med 9:983-4

21. Caeton AJ, Goetzman BW, Milstein JM, Bennett SH 1985 Effect of pulmonary hypertension on lung compliance in newborn lambs. Pediatr Res 19:400A

22. Stenmark KR, James SL, Voelkel NF, Toews WH, Reeves JT, Murphy RC 1983 Leukotriene C4 and D4 in neonates with hypoxemia and pulmonary hypertension. N Engl J Med 309:77-80

23. Riemenschneider TA Nielsen HC, Ruttenberg HD, Jaffe RB 1976 Disturbances of the transitional circulation: spectrum of pulmonary hypertension and myocardial dysfunction. J Pediatr 89:622-625

24. Murphy, JD, Aronovitz MJ, Reid LM 1986 Effects of chronic in utero hypoxia on the pulmonary vasculature of the newborn guinea pig. Pediatr Res 20:292-295

25. Drummond WH, Bissonnette JM 1978 Persistent pulmonary hypertension in the neonate: development of an animal model. Am $J$ Obstet Gynecol 131:761-763

26. Soifer SI, Kaslow D, Roman C, Heymann MA 1987 Umbilical cord compression produces pulmonary hypertension in newborn lambs: a model to study the pathophysiology of persistent pulmonary hypertension in the newborn. J Dev Physiol 9:239-252

27. Heymann MA, Rudolph AM 1976 Effects of acetylsalicylic acid on the ductus arteriosus and circulation in fetal lambs in utero. Circ Res 38:418-422

28. Levin DL, Mills LJ, Parkey M, Garriott J, Campbell W 1979 Constriction of the fetal ductus arteriosus after administration of indomethacin to the pregnant ewe. J Pediatr 94:647-650

29. Morin FC, Egan EA, Norfleet WT 1988 Indomethacin does not diminish the pulmonary vascular response of the fetus to increased oxygen tension. Pediatr Res 24:696-700

30. Friedman WF, Printz MP, Kirkpatrick SE, Hoskins EJ 1983 The vasoactivity of the fetal lamb ductus arteriosus studied in utero. Pediatr Res 17:331-337

31. deMello DE, Murphy JD, Arowovitz MJ, Davies P, Reid LM 1987 Effects of indomethacin in utero on the pulmonary vasculature of the newborn guinea pig. Pediatr Res 22:693-697

32. Terragno NA, Terragno DA, Pacholcyzk D, McGiff JC 1974 Prostaglandins and the regulation of uterine blood flow in pregnancy. Nature 249:57-58

33. Venuto RC, O'Dorisio T, Stein JH, Ferris TF 1975 Uterine prostaglandin E secretion and uterine blood flow in the pregnant rabbit. J Clin Invest 55:193

34. Dawes GS, Mott JC, Widdicombe JG, Wyatt DG 1953 Changes in the lungs of the newborn lamb. J Physiol 121:141-162

35. Morin III FC, Egan EA The effect of closing the ductus arteriosus on the pulmonary circulation of the fetal lamb. $\mathbf{J}$ Develop Physiol, in press

36. Berry TE, Muster AJ, Paul MH 1983 Transient neonatal tricuspid regurgitation: possible relation with premature closure of the ductus arteriosus. JACC 2:1178-1182

37. Momma K, Takao A 1987 In vivo constriction of the ductus arteriosus by nonsteroid antiinflammatory drugs in near-term and preterm fetal rats. Pediatr Res 22:567-572

38. Noel S, Cassin S 1976 Maturation of the contractile response of ductus arteriosus to oxygen and drugs. Am J Physiol 231:240-243 